\title{
Study of depression, anxiety and stress among first year Medical students in Government Medical College, Himachal Pradesh during COVID-19 pandemic
}

\author{
Susheela Rana', Onjal Taywade ${ }^{2}$, Vanita Sharma ${ }^{3}$, Monali Hiwarkar ${ }^{4}$ \\ ${ }^{1}$ Professor and Head, ${ }^{4}$ Associate Professor, Department of Anatomy, Shri Lal Bahadur Shastri Government Medical \\ College and Hospital, Ner Chowk, Mandi, Himachal Pradesh, India, ${ }^{2}$ Assistant Professor, Department of Biochemistry, \\ All India Institute of Medical Sciences, Bilaspur, Himachal Pradesh, India, ${ }^{3}$ Assistant Professor, Department of \\ Anatomy, Indira Gandhi Medical College and Hospital, Shimla, Himachal Pradesh, India
}

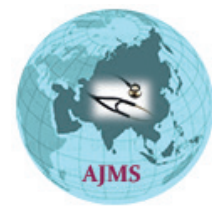

A B S T R A C T

Background: During COVID 19 pandemic many countries implied nationwide lockdown which affected academic and educational activities of medical students. We evaluated the level of depression, anxiety and stress among first MBBS students of Government Medical College, Himachal Pradesh. Aims and Objective: To estimate the level of depression, anxiety and stress among first MBBS students during COVID-19 pandemic and study its relationship with gender. Materials and Methods: A standard questionnaire DASS 21 (Depression Anxiety and Stress Scale) was administered to 110 first MBBS students of Government Medical College, Himachal Pradesh. The responses were collected via Google form and scores evaluated. Results: The overall score for depression was $10.44 \pm 5.1,10.94 \pm 5$ for anxiety and $12.29 \pm 5.3$ for stress. About $58 \%$ participants had depression, 74\% had anxiety \& $32 \%$ had stress in various grades of severity. Depression, anxiety \& stress was more among females as compared to males $(p<0.05)$. There was strong correlation among the scores of Depression, Anxiety \& Stress among the participants $(r>0.8)$. Conclusion: During this COVID-19 pandemic higher scores of depression, anxiety \& stress were recorded among the first year MBBS students; females having more scores than male students. This study highlights the importance of and need for routine screening of depression, anxiety and stress among medical students.

Key words: Depression; Anxiety; Stress; First MBBS; COVID-19 Pandemic

\section{Access this article online}

\section{Website:}

http://nepjol.info/index.php/AJMS DOI: $10.3126 /$ ajms.v12i6.36687

E-ISSN: 2091-0576

P-ISSN: $2467-9100$

Copyright (c) 2021 Asian Journal of Medical Sciences

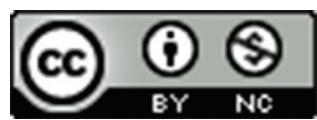

This work is licensed under a Creative Commons Attribution-NonCommercial 4.0 International License.

\section{INTRODUCTION}

In December 2019, a highly infectious acute severe respiratory syndrome caused by a novel coronavirus (SARS-CoV-2) emerged in Wuhan, China. Later, the disease spread to all corners of the world, and World Health Organization declared COVID-19 as a pandemic on March 11, 2020. ${ }^{1}$ During this pandemic many countries implied nationwide lockdown to curtail the disease spread. People struggled to manage their day-to-day activities and students were no exception. Multiple studies have shown a higher prevalence of anxiety, fear, depression, insomnia, somatization, and obsessive compulsive symptoms among various groups of health care workers. ${ }^{2-6}$ The uncertainty of this pandemic has caused considerable anxiety and fear around the world affecting all age groups ${ }^{7-10}$ Additionally, social distancing, quarantine and lockdown measures imposed by governments to control the spread of the virus have caused disruptions not only to businesses and employment but also to education. ${ }^{11}$ Medical education is amongst the most stressful educational activity. Stress can be defined as a process where environmental demands exceed individual's adaptive capacity, resulting in psychological and biological changes that may increase risk of diseases. Anxiety is a psychological state characterized by cognitive, somatic, emotional and behavioral components. Depression 
is a mood disorder characterized by symptoms like feeling of hopelessness, guilt, worthlessness, helplessness etc. ${ }^{12-15}$ An unexpected pause in education was experienced by the medical students as a result of closure of academic activities during COVID-19. The medical students were not able to attend their regular classes in this pandemic. And during this unprecedented times, fear of corona virus further added to the psychological problems associated with stress and anxiety.

Since limited data is available on psychological status of medical students from India during the pandemic, this study was planned to determine the presence and level of depression, anxiety and stress among first year students during the COVID-19 pandemic. This is the first of kind study to document the level of psychological issues faced by the students from the hilly regions of India.

\section{Aims and objective}

To assess and quantify the level of depression, anxiety and stress among first MBBS students of a government medical college in Himachal Pradesh during COVID-19 pandemic and study its relationship with gender.

\section{MATERIALS AND METHODS}

This was a cross-sectional observational study conducted among 120 first year MBBS students in the age range of 18 to 22 yrs. at a government medical college, Ner Chowk, Mandi, Himachal Pradesh from January 2021 to march 2021. Apparently healthy and willing 110 participants were included in this study as 10 students refused to participate in this study. A standard questionnaire DASS 21 (Depression Anxiety and Stress Scale) was administered to these students via online mode by Google form. URL was created which was sent to the students, after taking their valid informed consent. Students were explained regarding the questionnaire. Demographic details like age, gender etc. were noted.

DASS-21 is a 21 -item short version synthesized from the original 42 -item survey. ${ }^{15}$ This pre-validated questionnaire has seven items for each of the three scales designed to measure the negative emotional states of depression anxiety and stress. The questions 3, 5, 10, 13, 16, 17, and 21 form the depression scale; questions $2,4,7,9,15,19$, and 20 forms the anxiety scale while questions $1,6,8,11,12,14$, and 18 are covered in stress scale. A four-point severity/ frequency scale was used to rate the extent to which the respondents had experienced each symptom over the past week from "never" (0) to "most of the time" (3). The sum of the scores obtained was multiplied by two and then evaluated as per the severity rating index. The severe and very severe scores were clubbed together in this study for ease of analysis. Data was collected and analyzed using SPSS-20 version. The distribution pattern of results was checked by Kolmogorov- Smirnov test. Independent t-Test was used to study the difference between two groups i.e., males and females. Spearman's correlation was applied to assess the relation of Depression, Anxiety and Stress scores among male \& female participants during COVID-19 pandemic.

\section{RESULTS}

This study covered 110 participants (49 males and 61 females) with a mean age of $19.45 \pm 1.55$ years. DASS scores were calculated. Kolmogorov-Smirnov test implied the data was not normally distributed.

The results of these scores were classified as Normal, Mild, Moderate, Severe, Extremely Severe (Table 1). ${ }^{12-15}$ However, for analytical simplification, the severe and extremely severe scores were grouped together. Maximum no. of participants had normal Depression \& stress score, but had severe score for anxiety (Figure 1) The severity of symptoms was predominantly moderate in depression subscale, severe in anxiety subscale and mild in stress subscale. About $58 \%$ participants had depression, $74 \%$ had anxiety \& $32 \%$ had stress in various grades of severity. Depression, anxiety and stress was more among females as compared to males. Independent $\mathrm{t}$-Test showed a significant difference in the total DASS score $(p<0.05)$ between male and females (Table 2). Females had a higher score as compared to males (Table 3). Spearman's correlation coefficient was $>0.8$ i.e., there was strong correlation among the scores of Depressions, Anxiety \& Stress ( $\mathrm{p}<0.05)$ (Table 4).

\section{DISCUSSION}

A medical student in first year feels pride about choosing this noble profession that deals with human health. However, there is apprehension about the syllabus, cadaveric dissection and multiple exams. Being a medical student, requires sacrifice of social as well as personal life due to vast syllabus that demands long study hours leading to increased stress, anxiety and depression amongst these students. The COVID-19 global pandemic has resulted in

\begin{tabular}{lccc}
\multicolumn{4}{l}{ Table 1: Interpretation of DASS scores } \\
\hline Meaning & Depression & Anxiety & Stress \\
\hline Normal & $0-9$ & $0-7$ & $0-14$ \\
Mild & $10-13$ & $8-9$ & $15-18$ \\
Moderate & $14-20$ & $10-14$ & $19-25$ \\
Severe & $21-27$ & $15-19$ & $26-33$ \\
Extremely severe & $28+$ & $20+$ & $34+$ \\
\hline
\end{tabular}




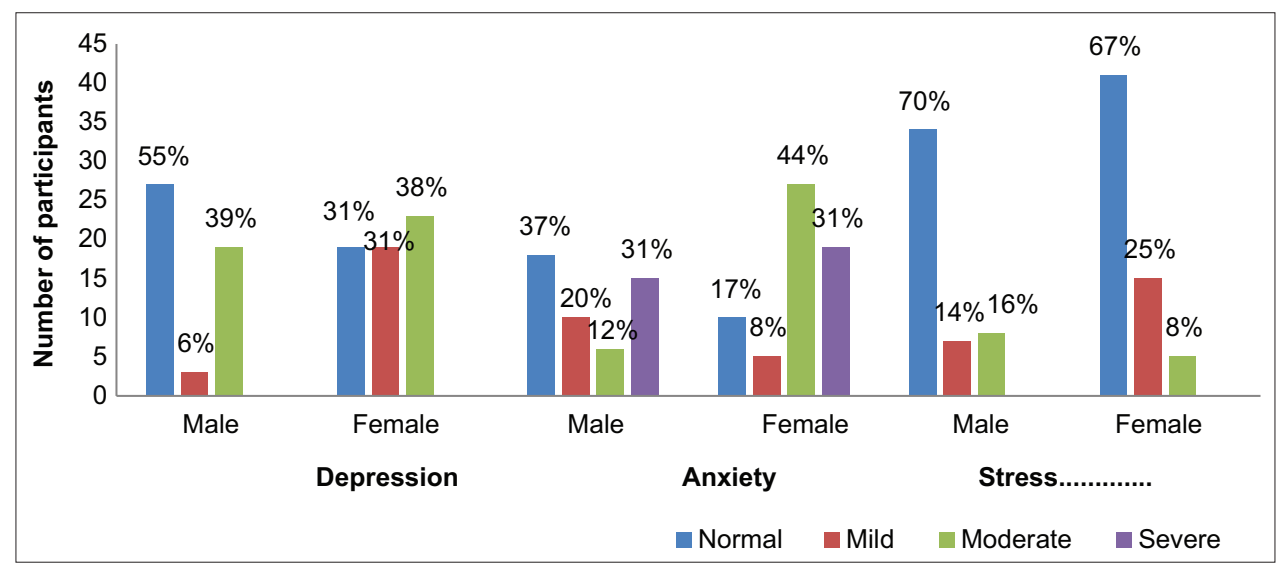

Figure 1: Distribution of participants based on DASS score during COVID-19 pandemic

\begin{tabular}{|c|c|c|c|c|c|}
\hline $\begin{array}{l}\text { DAS Score } \\
n=110\end{array}$ & Sex & Normal (mean \pm SD) & Mild (mean \pm SD) & Moderate (mean \pm SD) & Severe (mean \pm SD) \\
\hline \multirow[t]{2}{*}{ Depression } & Male & $4.85 \pm 2.12$ & $10 \pm 0$ & $16 \pm 1.76$ & - \\
\hline & Female & $6.31 \pm 2.80$ & $10.42 \pm 0.9$ & $15.86 \pm 1.81$ & - \\
\hline \multirow[t]{2}{*}{ Anxiety } & Male & $4.72 \pm 1.77$ & $8.4 \pm 0.51$ & $12.3 \pm 1.50$ & $17.2 \pm 1.47$ \\
\hline & Female & $3.20 \pm 2.52$ & $8.2 \pm 0.44$ & $11.85 \pm 1.58$ & $16.26 \pm 0.99$ \\
\hline \multirow[t]{2}{*}{ Stress } & Male & $9.02 \pm 0.64$ & $16.57 \pm 0.97$ & $21 \pm 1.06$ & - \\
\hline & Female & $9.9 \pm 4.04$ & $17 \pm 1.13$ & $19.8 \pm 0.83$ & - \\
\hline
\end{tabular}

\begin{tabular}{lccc}
$\begin{array}{l}\text { Table 3: Total and gender wise distribution of } \\
\text { DASS scores expressed as mean and standard } \\
\text { deviation }\end{array}$ \\
\hline DAS Score & $\begin{array}{c}\text { Depression } \\
\text { (mean } \pm \text { SD) }\end{array}$ & $\begin{array}{c}\text { Anxiety } \\
\text { (mean } \pm \text { SD) }\end{array}$ & $\begin{array}{c}\text { Stress } \\
\text { (mean } \pm \text { SD) }\end{array}$ \\
\hline $\mathrm{n}=110$ & $10.44 \pm 5.1$ & $10.94 \pm 5$ & $12.29 \pm 5.3$ \\
Male (49) & $9.49 \pm 5.7$ & $10.22 \pm 5.4$ & $12.06 \pm 5.6$ \\
Female (61) & $11.2 \pm 4.4$ & $11.51 \pm 4.6$ & $12.48 \pm 5.02$ \\
\hline
\end{tabular}

\begin{tabular}{lc}
$\begin{array}{l}\text { Table 4: Correlation between depression, } \\
\text { anxiety and stress }\end{array}$ \\
\hline Correlation between scores & r-value \\
\hline Depression and Anxiety & 0.86 \\
Anxiety and Stress & 0.84 \\
Depression and Stress & 0.82 \\
\hline
\end{tabular}

unprecedented public health challenge and has impacted the medical education. Stress, anxiety, and depression are overwhelmingly prevalent across the globe during this COVID-19 pandemic, students being no exemption. Due to high competitive nature of medical students, vast syllabus, long study hours, peer competition, sleep deprivation and academic pressure medical students are vulnerable to stress. ${ }^{13,17}$ In addition to this, factors associated with COVID pandemic viz lockdown, restrictions, social distancing, uncertainty and fear of losing near ones, news/ information on social media, sudden change from didactic to online mode of teaching, lack of practical sessions, unavailability of books etc. can influence students mental health conditions and lead to increased psychological issues amongst the students. Their resilience was further compromised by isolation and loss of social support from friends. Online mode for teaching lectures, practicals and assessment was the only possible solution to continue the academic activity. So, a sudden change to online sessions from didactic lectures created significant pressure on medical undergraduate students especially first MBBS students. The students were solely dependent on online study materials. Few students could not even carry all their books from hostels due to the announcement of sudden lockdown. However, there are many issues with online education and e-learning that need to be addressed. ${ }^{16}$

The findings of current study were not unexpected. These are in line with the study done by Chaudhuri et al., ${ }^{1}$ who found positive correlation between depression and stress scores with $r=0.765$; depression and anxiety scores with $r$ $=0.63$ and stress and anxiety scores with $\mathrm{r}=0.73$. Maximum $(70.92 \%)$ participants $(n=392)$ had normal stress score followed by $16.58 \%$ having mild stress scores. Maximum $(67.01 \%)$ participants had normal anxiety score followed by $16.33 \%$ having moderate anxiety scores and maximum of $55.1 \%$ participants had normal depression score followed by $17.85 \%$ having moderate depression scores. Vala NH et al., studied 250 first year medical students from western India and reported the prevalence of anxiety, stress and depression 
to be $17.20 \%, 15.60 \%$ and $10.80 \%$ respectively. ${ }^{14}$ Another study from India done earlier showed a greater number of participants had normal DASS scores during relaxed state as compared to the stressed state during the times of exams. ${ }^{12}$ Cao et al., could find that $25 \%$ of medical students in China showed different levels of anxiety. ${ }^{18}$ Rabiaah et al, surveyed 174 medical students and found that the female students had a significantly higher mean stress level than males $(p<0.001) .{ }^{19}$ Seventy-seven percent of participants reported minimal anxiety, $18.4 \%$ reported mild anxiety and none of them reported severe anxiety. Abdulghani et al., also proved that the prevalence of overall stress was significantly higher in female medical students than males and was highest during third year medical studies. ${ }^{20}$ About $22.3 \%$ of students had perceived severe stress as they did not prefer online learning. Safa et al., studied 425 Bangladeshi medical students using Hospital Anxiety and Depression Scale (HADS) and found that $65.9 \%$ of medical students had different levels of anxiety, $49.9 \%$ had varying degrees of depressive symptoms with $3.3 \%$ had suffered from severe depressive symptoms. ${ }^{21}$ Female students had a relatively more anxiety and depressive symptoms as compared to males. On the contrary, Ansari et al., included 500 medical clerks and interns in his cross-sectional study and used Beck Anxiety Inventory Beck Anxiety Inventory questionnaire. ${ }^{22}$ However, they concluded that depression and anxiety did not significantly differ among Iranian medical students before and after the COVID-19 outbreak. But, somatic symptoms of depression were more common and anxiety was more prevalent among females than in males $(\mathrm{p}<0.001)$. Moreover, no significant difference was observed between genders in depression. An important finding of this study was higher DASS scores of female students than males, which highlights the necessity of creation of institute level support groups.

Thus, COVID-19 pandemic seems to have induced stress in medical students which can be perceived as change in their attitude, behavior as well as psychology. However, different assessment methods and different situations might be responsible for varying outcomes among these studies. These medical students will become doctors tomorrow. Their poor mental makeup poses threat to future health care. Necessary psychological support was not available to medical students during the time of social distancing. Moreover, the current healthcare system was busy managing the COVID-19 pandemic and the issue of mental status of medical students was often neglected. In this study, higher scores of depressions, anxiety and stress among the first year MBBS students were not surprising. But, as the sample size of the present study was less, multicentric studies on a larger sample size are necessary to study the real impact of the COVID crisis on the psychology of medical students.
This study may generate baseline data to understand student's mental status so that academicians and policymakers can plan and intervene to resolve such issues during pandemics or similar situations. Early detection and intervention may help in preventing and minimizing the effects of distress on the students. It is also recommended to assess and understand the psychological needs of medical students and establish support programs for medical students during this infectious disease outbreak.

There is urgent need for routine screening of depression, anxiety and stress among medical students for early detection and better management of psychological issues confronted during tough times of this corona pandemic.

\section{CONCLUSION}

The COVID-19 pandemic has impacted the training and academics of medical students. Higher scores of depressions, anxiety and stress among the first year MBBS students were found; females had more scores than male students. However, the findings of this study need validation from large sample studies. Nonetheless, attention to the mental health status of these students is of immense importance to make them ready for future challenges. This study highlights the importance of and need for routine screening of depression, anxiety and stress among medical students.

\section{Limitations of the study}

In DASS-21 questionnaire, bias due to exaggeration or underestimation of the findings perceived by the participants cannot be ruled out. Small sample size warrants the results to be validated on larger population before extrapolation. Studying one or more biological variables like stress hormone level could have given more insight on better estimation of these psychological issues, however the sampling was not possible during the COVID pandemic.

\section{ACKNOWLEDGMENTS}

The authors express sincere thanks to the study participants.

\section{REFERENCES}

1. Chaudhuri A, Mondal $T$ and Goswami A. Prevalence of depression, anxiety, and stress among medical students in a developing country during the COVID-19 pandemic: A pilot study. J Sci Soc. 2020; 47:158-163.

https://doi.org/10.5455/ijmsph.2020.09244202017092020

2. Lu W, Wang H, Lin $Y$ and Li L. Psychological status of medical workforce during the COVID-19 pandemic: A cross-sectional study. Psychiatry Res. 2020; 288:112936.

https://doi.org/10.1016/j.psychres.2020.112936 
3. Zhang WR, Wang K, Yin L, Zhao WF, Xue Q, Peng M, et al. Mental Health and Psychosocial Problems of Medical Health Workers during the COVID-19 Epidemic in China. Psychother Psychosom. 2020;89(4):242-250.

https://doi.org/10.1159/000507639

4. Chen Y, Zhou H, Zhou Y and Zhou F. Prevalence of self-reported depression and anxiety among pediatric medical staff members during the COVID-19 outbreak in Guiyang, China. Psychiatry Res. 2020; 288:113005.

https://doi.org/10.1016/j.psychres.2020.113005

5. Lai J, Ma S, Wang Y, Cai Z, Hu J, Wei N, et al. Factors Associated with Mental Health Outcomes Among Health Care Workers Exposed to Coronavirus Disease 2019. JAMA Netw Open. 2020;3(3): e203976.

https://doi.org/10.1001/jamanetworkopen.2020.3976

6. Shah SMA, Mohammad D, Qureshi MFH, Abbas MZ and Aleem S. Prevalence, Psychological Responses and Associated Correlates of Depression, Anxiety and Stress in a Global Population, During the Coronavirus Disease (COVID-19) Pandemic. Community Ment Health. 2021; J 57, 101-110. https://doi.org/10.1007/s10597-020-00728-y

7. Wang C, Pan R, Wan X, Tan Y, Xu L, Ho CS, et al. Immediate psychological responses and associated factors during the initial stage of the 2019 coronavirus disease (COVID-19) epidemic among the general population in China. Int J Environ Res Public Health. 2020;17(5).

https://doi.org/10.3390/ijerph17051729

8. Qiu J, Shen B, Zhao M, Wang Z, Xie B and Xu Y. A nationwide survey of psychological distress among Chinese people in the COVID-19 epidemic: implications and policy recommendations. Gen Psychiatr. 2020;33(2): e100213.

https://doi.org/10.1136/gpsych-2020-100213

9. Wang $C$, Pan R, Wan X, Tan $Y, X u$ L, Mclntyre I, et al. A longitudinal study on the mental health of general population during the COVID-19 epidemic in China. Brain Behav Immun. 2020; 87:40-48.

https://doi.org/10.1016/j.bbi.2020.04.028

10. Bueno - Notivol J, Gracia-García P, Olaya B, Lasheras I, LópezAntón R and Santabárbara J. Prevalence of depression during the COVID-19 outbreak: a meta-analysis of community-based studies. Int J Clin Health Psychol. 2020;

https://doi.org/10.1016/j.ijchp.2020.07.007

11. Saddik B, Hussein A, Sharif-Askari FS, Kheder W, Temsah MH, Kautiach RA, et al. Increased Levels of Anxiety Among Medical and Non-Medical University Students During the COVID-19 Pandemic in the United Arab Emirates. Risk Manag Healthc Policy. 2020; 13:2395-2406.

https://doi.org/10.2147/RMHP.S273333

12. Hiwarkar M, Prasad A, Pant MK and Taywade O. Assessment of Negative Emotional States of Depression, Anxiety and
Stress Among First MBBS students-A Cross Sectional Study. Walawalkar International Medical Journal. 2020; 7(1): 29-37.

13. Kumar SD, Kavitha HS, Kulkarni P, Siddalingappa $H$ and Manjunath R. Depression, anxiety and stress levels among medical students in Mysore, Karnataka, India. Int J Community Med Public Health. 2016; 3:35962.

https://doi.org/10.18203/2394-6040.ijcmph20151591

14. Vala NH, Vachhani MV and Sorani AM. Study of anxiety, stress, and depression level among medical students during COVID-19 pandemic phase in Jamnagar city. Natl J Physiol Pharm Pharmacol. 2020; 10(12): 1043-1045. https://doi.org/10.5455/njppp.2020.10.07205202031072020

15. Lovibond SH, Lovibond PF. (1995) Manual for the Depression Anxiety Stress Scales. 2nd ed. Sydney, N.S.W., Psychology Foundation of Australia,1995. https://doi.org/10.1037/t39835-000

16. Hiwarkar M and Taywade O. Assessment of knowledge, attitude and skills towards e-learning in first year medical students. Int $\mathrm{J}$ Res Med Sci. 2019; 7:4119. https://doi.org/10.18203/2320-6012.jirms20194977

17. Wahed Abdel WY and Hassan SK. Prevalence and associated factors of stress, anxiety and depression among medical Fayoum University students. Alexandria Journal of Medicine. 2017; 53:77-84.

https://doi.org/10.1016/j.ajme.2016.01.005

18. Cao W, Fang Z, Hou G, Han M, Xu X, Dong J, et al. The psychological impact of the COVID-19 epidemic on college students in China. Psychiatry Res. 2020; 287:112934. https://doi.org/10.1016/j.psychres.2020.112934

19. Al-Rabiaah A, Temsah MH, Al-Eyadhy AA, Hasan GM, Zamil FA, Subaei SA, et al. Middle East Respiratory Syndrome-Corona Virus (MERS-CoV) associated stress among medical students at a university teaching hospital in Saudi Arabia. J Infect Public Health. 2020;13(5):687-691. https://doi.org/10.1016/j.jiph.2020.01.005

20. Abdulghani HM, Sattar K, Ahmad T and Akram A. Association of COVID-19 Pandemic with undergraduate Medical Students' Perceived Stress and Coping. Psychol Res Behav Manag. 2020; 13:871-881. https://doi.org/10.2147/PRBM.S276938

21. Safa F, Anjum A, Hossain S, Trisa TI, Alam SF, Rafi MA, et al. Immediate psychological responses during the initial period of the COVID-19 pandemic among Bangladeshi medical students, Children and Youth Services Rev. 2021;122: 105912. ISSN 0190-7409. https://doi.org/10.1016/j.childyouth.2020.105912

22. Nakhostin-Ansari A, Sherafati A, Aghajani F, Khonji MS, Aghajani R, and Shahmansouri N. Depression and Anxiety among Iranian Medical Students during COVID-19 Pandemic. Iran J Psychiatry. 2020;15(3):228-235. https://doi.org/10.18502/ijps.v15i3.3815

\footnotetext{
Author's Contribution:

VS, MH- Contribution to conception and design; SR, MH- Designing the study, Acquisition, analysis and interpretation of data; OT- Statistical analysis; OT, VS- Drafting manuscript, revising manuscript critically for important intellectual content; $\mathbf{M H}$ - Accountable for all aspects of the research work and publication. All authors have approved of the version of manuscript to be published.

Work attributed to:

Shri Lal Bahadur Shastri Government Medical College and Hospital,Ner Chowk, Mandi, Himachal Pradesh, India.

Orcid ID

Dr Onjal Taywade- (i) https://orcid.org/0000-0002-3373-0363

Dr. Monali Hiwarkar- (1) https://orcid.org/0000-0001-9141-8856

Source of funding: None, Conflict of interest: None.
} 